\title{
Strategic Needs of Water on the Yukon: An Interdisciplinary Approach to Studying Hydrology and Climate Change in the Lower Yukon River Basin
}

\section{Introduction}

Strategic Needs of Water on the Yukon (SNOWY) is an interdisciplinary research project funded by the National Science Foundation (NSF; http://www.nsf.gov/). The SNOWY team is made up of a diverse group of researchers from different backgrounds and organizations. This partnership between scientists from different disciplines (hydrology, geography, and social science), government agencies, nonprofit organizations, universities, and Lower Yukon River Basin (LYRB) and Yukon-Kuskokwim (YK) Delta communities provided an opportunity to study the effects of climate change using a holistic approach. The Arctic and Subarctic are experiencing environmental change at a rate faster than the rest of the world, and the lack of historical baseline data in these often remote locations makes understanding and predicting regional climate change difficult. This project focused on collecting data to fill in these gaps by using both quantitative and qualitative methodologies to tell the story of environmental change in this region as told by the physical data and the people who rely on this landscape.

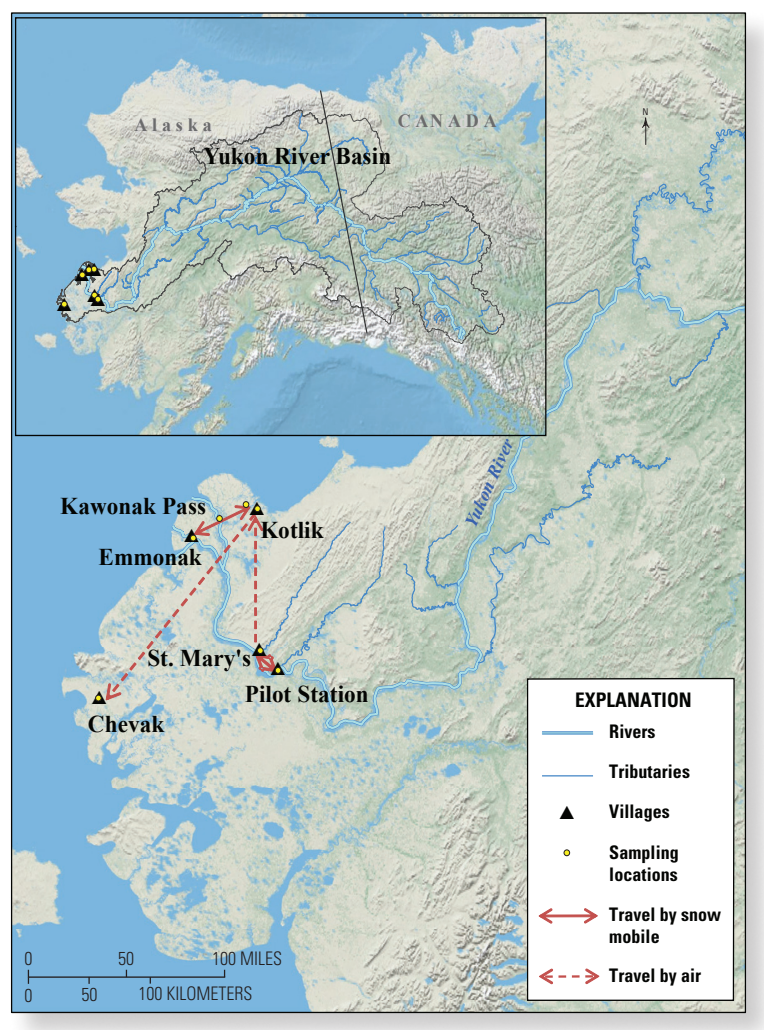

Figure 1. Location of villages visited for field work. Base map copyright: (C) 2011 National Geographic Society, i-cubed.

\section{Study Location}

Field work was conducted in five villages located in the Lower Yukon River Basin (LYRB) and Yukon-Kuskokwim (YK) Delta Region. The villages were selected based on their participation in the U.S. Geological Survey-Yukon River Inter-Tribal Watershed Council (USGS-YRITWC) water-quality monitoring program (http://pubs.usgs.gov/ $f_{s} / 2010 / 3020 /$ ) and Active Layer Network (ALN) project (https://sites.google.com/a/yritwc.org/active-layer-network/; http://pubs.usgs.gov/fs/2011/3040/) as well as their unique hydrology as part of the Yukon Delta. Comprehensive field campaigns focused on both physical and social sciences were conducted in St Mary's, Kotlik, and Chevak. Additional hydrologic data were collected at Emmonak and Pilot Station (fig. 1). Additional qualitative data were also collected at Pilot Station in the form of interviews.

All of the villages are Yup'ik communities, with the exception of Chevak, which is a Cup'ik community whose inhabitants speak the Cup'ik dialect of the Yup'ik language and identify as a distinct population from the Yup'ik. The populations of the communities range from the smallest, St Mary's (531), to the largest, Chevak (982; 2010 Census, http://www.census.gov/2010census/). Each village has one school, which serves all grade levels in the community. All of the villages are located on the banks of the Yukon River or one of its major tributaries. Kotlik is the village nearest the coast (fig 2); it is located roughly 10 miles from the Bering Sea Coast. Although also part of the Yukon River Delta system, the village of Chevak and its surrounding lakes have the least influence from the larger basin (fig. 3).

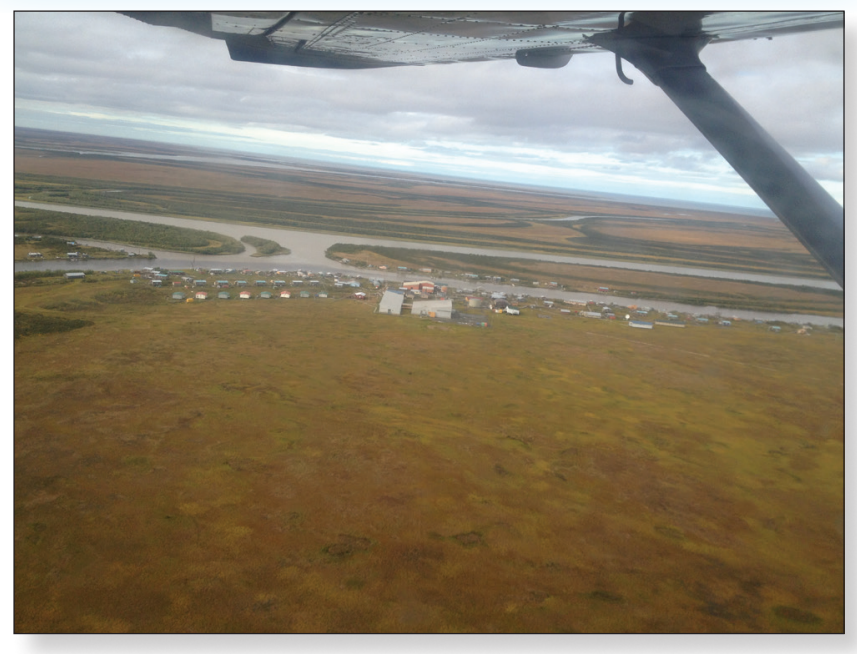

Figure 2. Aerial view of the Kotlik Slough running through the village of Kotlik and the Yukon River main stem to the west. 


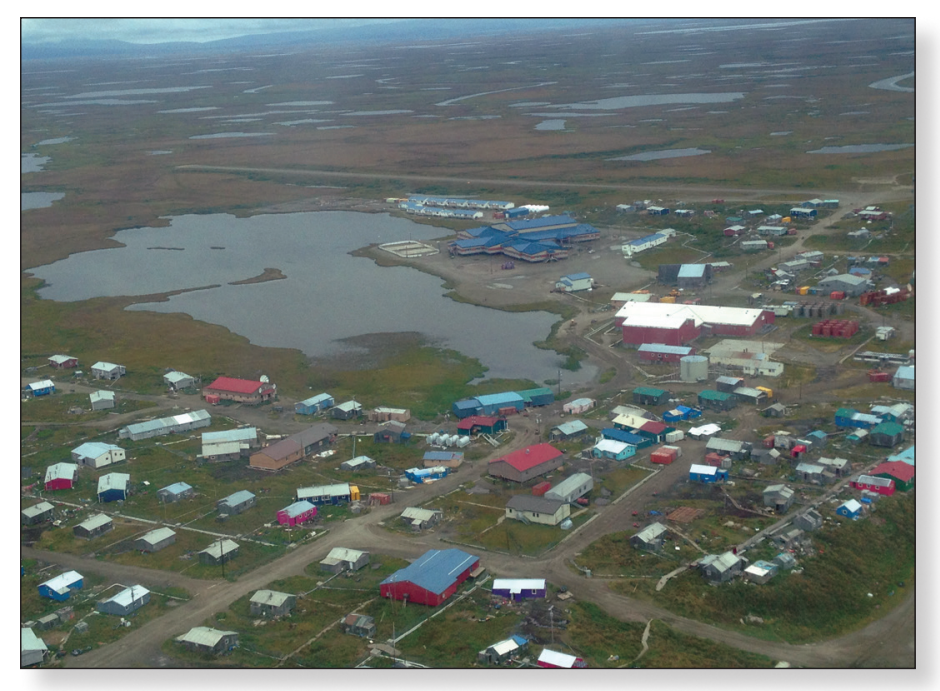

Figure 3. Aerial view of Chevak.

\section{Methodology Overview}

A team of seven researchers from various institutions - the U.S. Geological Survey (USGS; http://www.usgs.gov/), the U.S. Forest Service (USFS; http://www.fs.fed.us/), the Yukon River Inter-Tribal Watershed Council (YRITWC; $h t t p: / / w w w$. yritwc.org/), and Colorado State University (CSU; http://www. colostate.edu/) - traveled to the aforementioned villages and conducted field work in February 2014. Comprehensive field campaigns included under-ice river-water sample collection, snowpack measurements, interviews with community experts, and a participatory mapping workshop. In each village targeted for comprehensive field work, a large school and community outreach component focused on educating both students and community about environmental-science activities conducted in their village. In an effort to enhance scientific data that supports climate-change research within these areas, students participated in collecting key under-ice water samples and performing critical snowpack measurements.

Community meetings were held in the three villages targeted for comprehensive field work (fig. 4). A brief presentation

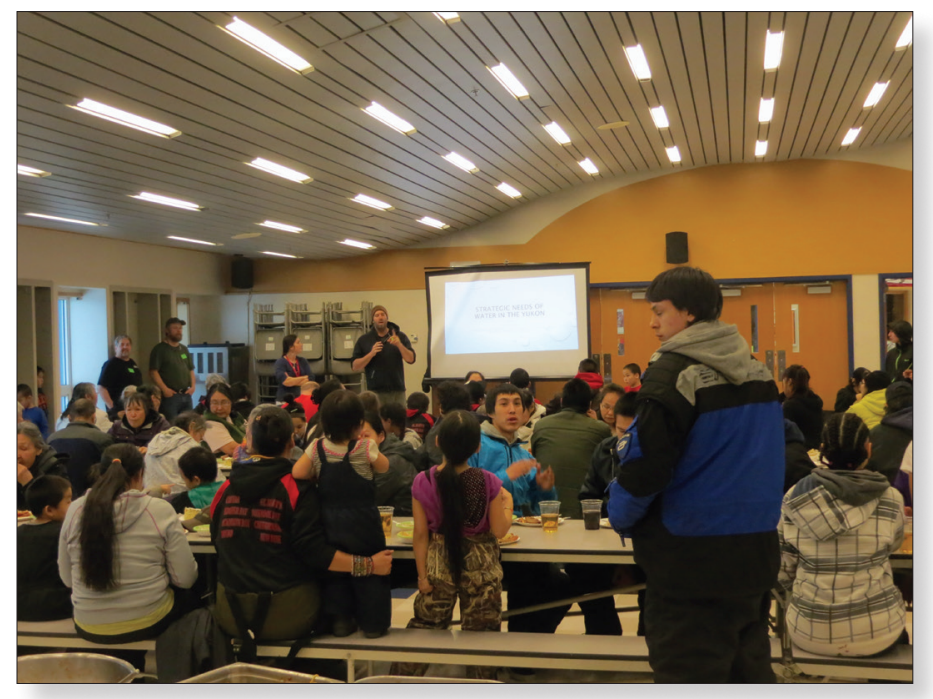

Figure 4. Community meeting in Chevak. was given that described the project and the goals of the interviews and mapping workshop. The meeting was also used to recruit interview participants, arrange a mapping workshop, and request volunteers for the Community Collaborative Rain, Hail, and SNOW network (CoCoRaHS). This network is a grassroots network of volunteers that measure precipitation in their community (for more information visit: http://www.cocorahs.org/).

\section{School Outreach}

In St. Mary's, Kotlik, and Chevak, the field work began with a day of outreach at the community's school. Members of the research team gave lectures to a group of high school students on water-quality research and snow hydrology, specifically as it relates to the LYRB and YK Delta Regions. The students later conducted field work to collect under-ice water samples to be analyzed at the USGS National Research Program (NRP) labs. Snowpack measurements were made by the students at the ALN site in their village (fig. 5).
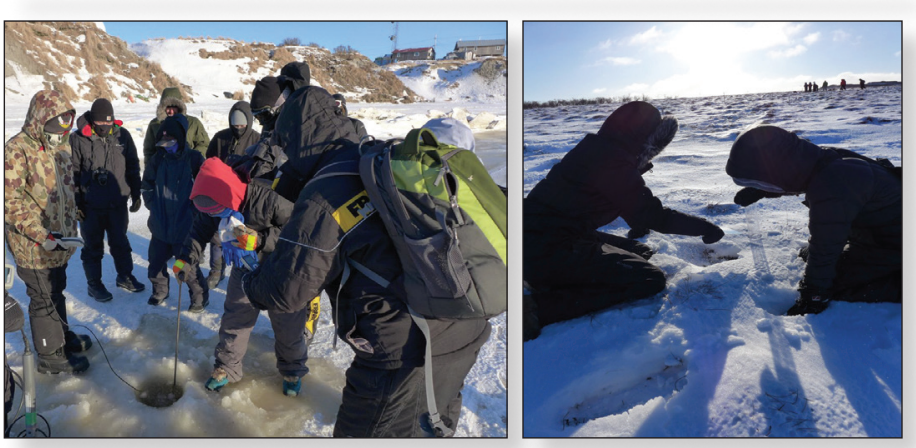

Figure 5. Left: Under-ice water sampling by students, Ningliqvak River, Chevak. Right: Snow water equivalent measurements by students, Active Layer Network site, St. Mary's.

In Kotlik and Chevak, an additional lecture introduced a project called "Photovoice," in which the students and teachers could participate. Photovoice is a participatory photography project in which participants choose an environmental issue of interest to document with photographs and text. In Kotlik, a teacher and group of students chose to document the effects of a recent flood which damaged structures in the community. Researchers returned to the villages in early May 2014 and held a follow-up meeting with the teachers and principals at these schools to discuss future outreach with students as well as next steps for Photovoice.

\section{Water Sampling and Snow Measurements}

In addition to the water samples collected and snowpack measurements made by students, water samples and river bank snowpack measurements were also collected at four other sites on the Yukon River and the three main distributaries into the Bering Sea. The first of these samples was taken in Pilot Station (fig. 6). The Pilot Station water-quality sampling site represents the outlet of the Yukon River before entering the delta. A full suite of water quality samples, including mercury, were processed from this site. Under-ice Acoustic Doppler Current Profiler (ADCP) discharge measurements were attempted at all sites, but the extreme weather conditions $\left(-46^{\circ} \mathrm{C}\right.$ wind chill) 
caused equipment malfunctions that prevented a measurement. The Pilot Station site is equipped with a USGS gaging station; thus, discharge and water quality data, real time and historical, are available online at http://waterdata.usgs.gov/ak/nwis/ $u v /$ site no $=15565447 \&$ PARAmeter_cd $=00065,00060$.
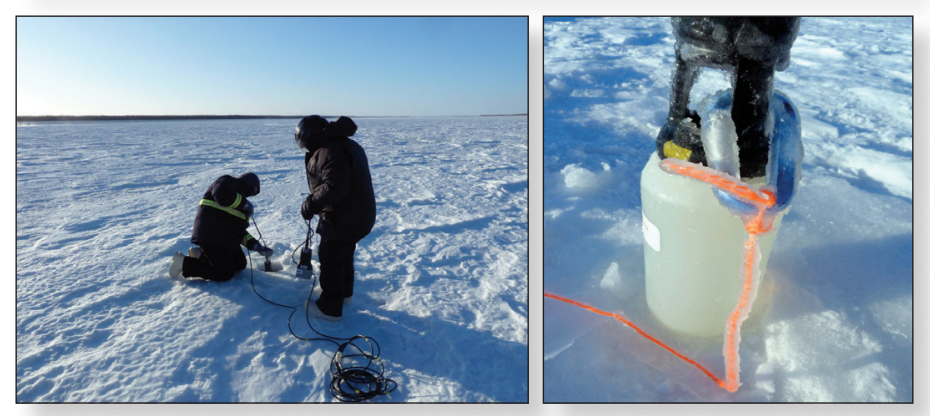

Figure 6. Collecting under-ice water samples at Pilot Station during sub-zero (wind chill $-46^{\circ} \mathrm{C}$ conditions. Note the ice accumulation on the carabineer attached to the water sampling bottle.

Subsequent samples were collected at the three main distributaries of the Yukon River (near Kotlik, Kawonak Pass, and near Emmonak) and very close to the Bering Sea within six days of the Pilot Station sample. This approach to water quality sampling is known as a "synoptic." Essentially it is a "snap shot" in which samples are collected in a defined reach in a very short time frame under constant conditions (that is, winter base flow). To our knowledge, this represents the first wintertime synoptic sampling of the Yukon River from inland outlet (Pilot Station) through the delta to the Bering Sea. This unique data set will provide insight in the dynamics of biogeochemical processes occurring between the Yukon River outlet and the Bering Sea with implications for nutrient transport and effects of climate change.

\section{Participatory Mapping}

Participatory mapping workshops were conducted in the three villages targeted for comprehensive field work. Six people participated in St. Mary's, sixteen in Kotlk, and eighteen in Chevak. First, the participants were asked to agree on a list of common landmarks to include in their hand-drawn maps. Next, the participants were separated into four groups and asked to

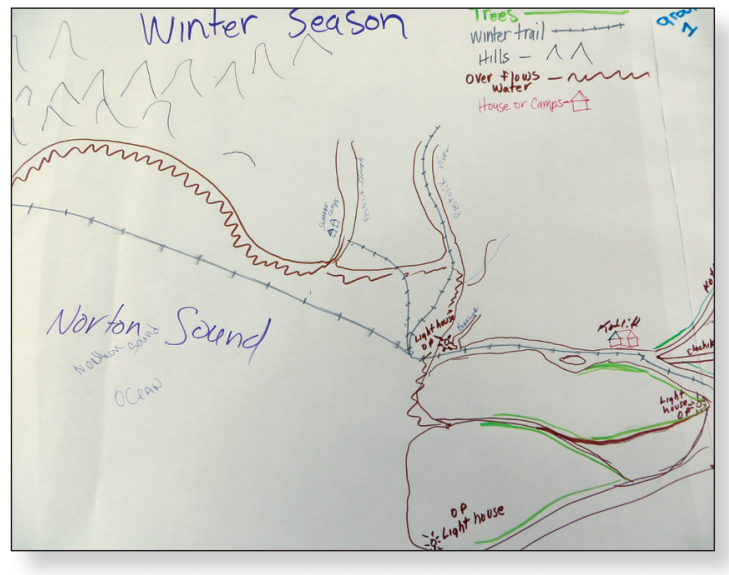

Figure 7. A winter season map made in Kotlik. come up with a seasonal calendar of subsistence resources and community activities. The groups then each presented one season to the rest of the groups. If activities or resources were overlooked, the rest of the group corrected them and they were added to the calendar. Then the groups were each asked to create a map based on the season they just presented (fig. 7). For example, if they presented a calendar of subsistence resources for winter, they drew a map of the community indicating where winter resources were harvested. Finally, as each group presented their maps to the larger group, they received feedback, and again elements that had been overlooked were added to the maps.

\section{Interviews}

Interviews were conducted with community members in four of the villages visited: St. Mary's, Pilot Station, Kotlik, and Chevak. A total of 55 community members participated in interviews: seven participants in St. Mary's, nine participants in Pilot Station, twenty-four participants in Kotlik, and fifteen participants in Chevak. The gender of participants was nearly evenly split: there were 25 female and 30 male participants. The participants' ages ranged from 24 years old to people in their $70 \mathrm{~s}$ and $80 \mathrm{~s}$. However, the majority of the interview participants were between the ages of 40 and 65 .

Many interview participants were recruited by our local Tribal Contacts in the community; this was especially true in Kotlik, Chevak, and Pilot Station, where our Tribal Contacts provided us with a list of interview candidates. Additionally, in each community (with the exception of Pilot Station), participants were recruited at the community meeting. Mapping participants were also asked to give one-on-one follow-up interviews in all villages, which proved to be a valuable method of recruitment, especially in St. Mary's, where difficulties using other recruitment methods were encountered. Interviews were conducted in people's homes (fig. 8), the Tribal Council offices, at the village school, and at the city hall in St. Mary's. Participants received an honorarium for participating in an interview. As word spread throughout the community, interested candidates sought us out and inquired about interviews.

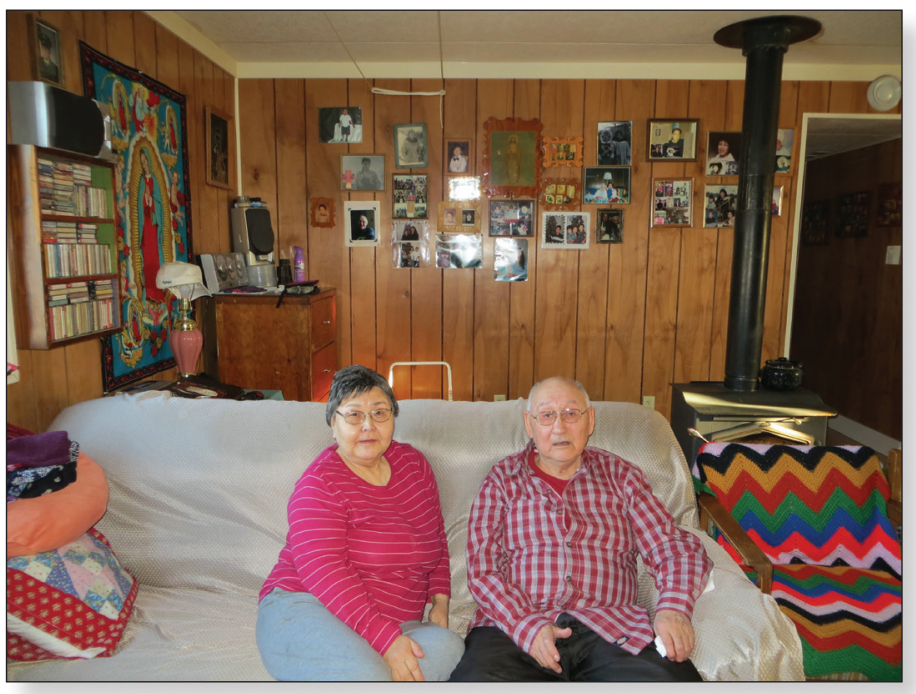

Figure 8. Louise Crane and her husband Isidore Mike in their home in St. Mary's after participating in an interview. 
Interview questions covered the themes of seasonal shift and water resources (in all its forms: snow, ice, lakes, rivers, ocean, and other forms of precipitation). The theme of seasonal shift was explored by asking questions about when seasons typically begin, what signals the participants noted as being the start of a new season, and whether there has been a change in expected or "typical" weather for each season. Water resources were discussed by asking the interview participants to describe key qualitative features about the river, including river ice and precipitation, particularly snow. Interviewers refrained from using the term "climate change" during the interview in an effort to remove potential bias and understand what the interview respondents attributed changes to, if a change was noted. Finally, participants were asked to describe their community and what they most valued about their community. This value question helped provide an indication of the impact of present climate change, and what effects future climate change may have on the community.

\section{Conclusion}

The data collected during this project will be developed into a number of products for both the Yukon village communities and the scientific community. Researchers from the

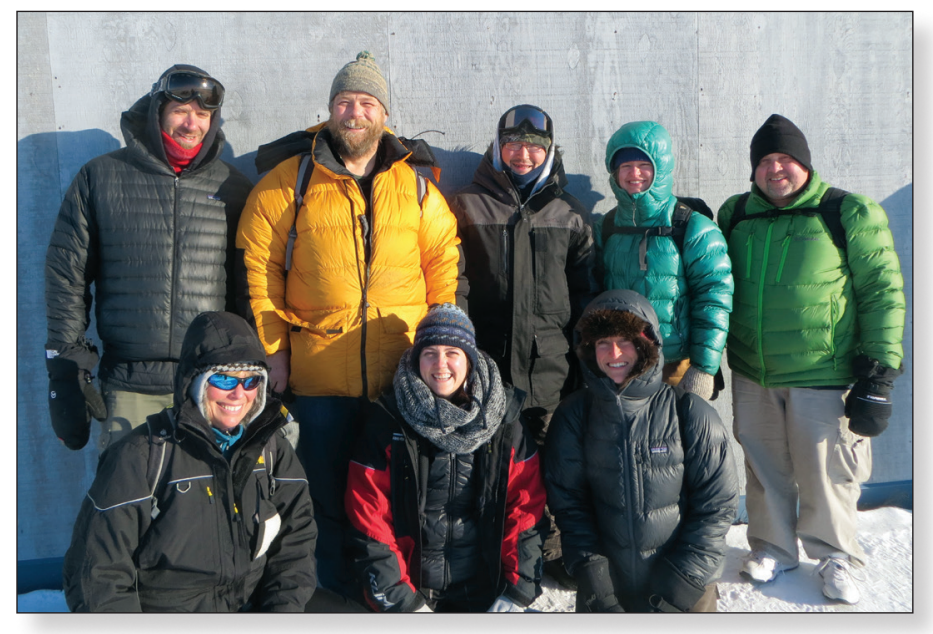

Figure 9. The Strategic Needs of Water on the Yukon research team and Kotlik Tribal Partner. Left to right, back row: Ryan Toohey (U.S. Geological Survey [USGS]), Kelly Elder (U.S. Forest Service; http://www.fs.fed.us/research/people/profile.php?alias=kelder), Victor Tonuchuk Jr. (Kotlik Tribal Council), Maggie Massey (Yukon River Inter-Tribal Watershed Council [YRITWC]; http://www.yritwc. org/Departments/Science.aspx), and Paul F. Schuster (USGS; https://profile.usgs.gov/pschuste). Left to right, front row: Melinda Laituri (Colorado State University; http://warnercnr.colostate.edu/ ess-people/faculty), Nicole Herman-Mercer (USGS), and Elli Matkin (YRITWC; http://www.yritwc.org/Departments/Science.aspx).
SNOWY team (fig. 9) are currently working with the Exchange for Local Knowledge and Observations of the Arctic (http://eloka-arctic.org/) to create an online atlas where these data will be housed and can be accessed by LYRB and YK Delta community members. The data that will be accessible from the atlas include the water-quality data, snowpack data, photos, interview text and audio, maps created by community members, and video from interviews and field work. With the permission of the LYRB and YK Delta communities involved, this atlas will be accessible to the public, and become a place where the knowledge that these community members hold about their environment and the observations of change they are experiencing can be shared with the world.

\section{Acknowledgments}

It is an honor to acknowledge all the participating Tribes and members of the communities that participated in this research. Their openness in sharing their knowledge with us and assisting with the research made this a truly rewarding project and has formed the basis for a long-term partnership between the researchers and the communities. We would also like to acknowledge the USGS Office of Tribal Relations and the USGS National Research Program for funding the publication of this Fact Sheet.

Indigenous Communities Involved

Kotlik Traditional Council

Hamilton Tribal Council

Bill Moore's Slough Elder Council

Pilot Station Traditional Council

Yupiit of Andreafski

Algaaciq Tribal Council

Chevak Traditional Council

For additional information contact:

Nicole M. Herman-Mercer

U.S. Geological Survey

3215 Marine Street, Suite E127

Boulder, Colorado 80303

Phone: (303) 541-3012

Fax: (303) 541-3084

Email:nhmercer@usgs.gov

Paul F. Schuster

U.S. Geological Survey

3215 Marine Street, Suite E127

Boulder, Colorado 80303

Phone: (303) 541-3052

Fax: (303) 541-3084

Email:pschuste@usgs.gov

\section{Cooperators}

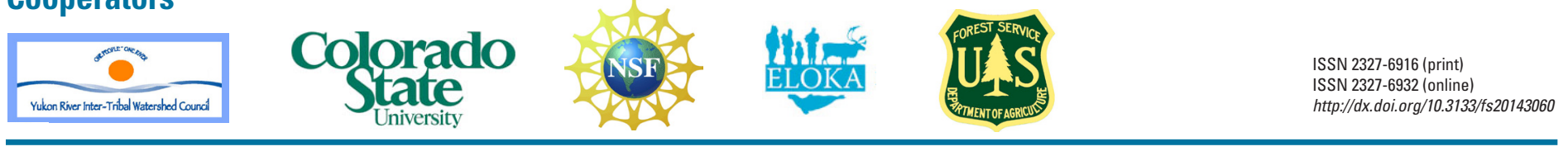

